\title{
An analytical study of maternal death at tertiary care hospital
}

\author{
Goswami KD ${ }^{1}$, Dudhrejia $\mathrm{KM}^{2}$, Parmar $\mathrm{PH}^{3}$, Kataria $\mathrm{A}^{4}$ \\ ${ }^{1}$ Dr K D Goswami, Associate Professor, ${ }^{2}$ Dr K M Dudhrejia, Associate Professor, ${ }^{3}$ Dr Prakash H. Parmar, Assistant \\ Professor, ${ }^{4}$ Dr Arvind Kataria, Resident. All are affiliated with Department of Obstetrics and Gynecology, PDU Medical \\ College, Rajkot, Gujrat, India
}

Address for correspondence: Dr K D Goswami, Email: drparmarobgy@gmail.com

\begin{abstract}
Background: Maternal mortality is one of the important public health challenges faced by India today. Being a country with highest number of maternal deaths worldwide, i.e. 63, 000 per year and having a Maternal Mortality Ratio of 230/1,00,000 live births, it is a matter of grave concern and high priority. Objective: To study the MMR and common causes leading to death, so that improving maternal health and reducing maternal mortality rate significantly. Methods: We have done Retrospective Observational study in Department of Obstetrics \& Gynecology, P.D.U. Medical College, Rajkot between 1st August 2012 to 31 ${ }^{\text {st }}$ July 2014. Results: There were 30 Maternal Deaths during Study Period of 2 years in the Institute. Maternal Mortality Ratio of the Study Centre was 219 per lakhs live births. Out of 30 maternal deaths 21-30 yrs age group having $77 \%$ of maternal death while $67 \%$ belongs to lower socio-economical class. Out of 30 , $15(50 \%)$ died within 24 hrs of delivery. Hemorrhage was the most common cause in 15(50\%) cases while others were Eclampsia (13\%), septicemia (11\%), ARDS (13\%), others (13\%). Conclusions: Maternal Mortality Ratio of the Study Centre was 219 per lakhs live births. Hemorrhage was the most common cause. Early registration, regular antenatal care, early referral are key things in reduction of maternal deaths. Facility based maternal death review (FBMDR) should be done at every institute level to find out the deficit and thus helping in reduction of maternal deaths.
\end{abstract}

Keywords: Maternal Mortality, Maternal Mortality Ratio, Facility based Maternal Death Review (FBMDR)

\section{Introduction}

Maternal mortality reflects women's basic health status, access to health care and the quality of care that has been provided. Although India has achieved a $59 \%$ reduction in maternal mortality in 2008 as regards to 1990 levels, still it is behind the World Health Organization's (WHO) fifth Millennium Development Goal (MDG 5) of $75 \%$ reduction of 1990 levels by 2015 which comes out to be approximately $5.5 \%$ reduction per year [1]. If we have to expedite this process and catch up with the WHO target, then we have to count beyond the numbers and review each and every maternal death for its possible cause and contributing factors, many of which are avoidable [2].

Maternal mortality has been higher in developing countries than in developed countries. In India the lowest MMR is in Gujarat followed by Tamil Nadu [3].

Manuscript received: $14^{\text {th }}$ Sept 2015

Reviewed: $24^{\text {th }}$ Sept 2015

Author Corrected: $8^{\text {th }}$ Oct 2015

Accepted for Publication: $20^{\text {th }}$ Oct 2015
FMBDR in resource poor settings is one of the oldest and the most documented method that can be effective in improving emergency obstetric care and maternal outcomes.Therefore FBMDR was thought to be the most appropriate to study the causes and factors of maternal mortality with an intention to find out why deaths occur in women during childbirth even after hospital admission [4].

Our study was designed to find out common causes of maternal death in tertiary care hospital and thus evaluating FBMDR in our institute.

\section{Methods}

We have done Retrospective Observational study in Department of Obstetrics \& Gynecology, P.D.U. Medical College, Rajkot between 1st August 2012 to $31^{\text {st }}$ July 2014.

Maternal death has been defined by the ninth and tenth revisions of the International Statistical Classification of 
Diseases and Related Health Problems (ICD) as, "the death of a woman while pregnant or within 42 days of termination of pregnancy, irrespective of the duration and the site of the pregnancy, from any cause related to or aggravated by the pregnancy or its management but not from accidental or incidental causes"[2,5].

This definition has been used throughout the study. The study population does not include those women who had died as a result of non-maternal causes or on their way to this hospital. Data collection was done through in-depth interviews of Health Care Providers (HCPs) associated with maternal deaths. The HCPs were consultants, post-graduates and nurses of Obstetrics and Gynaecology (O\&G) department who were present with the woman in the treatment process through her time to death.

Appropriate questionnaires and schedules for FMBDR by WHO were adopted and modified for preparing the questionnaire and data extraction form [2].

The collected data were compiled, cleaned and analysed using MS Excel 2007. Analysis of each and every maternal death was done by consultants to establish the underlying, immediate and contributory cause of death, type of maternal deaths - direct or indirect, whether the maternal deaths were avoidable and the contributory factors for such deaths.

\section{Results}

The analysis of data obtained from the Medical Record Extraction Form revealed that there were 30 maternal deaths during the 2 year. Each case was evaluated on bases of multiple parameters such as age, parity, socioeconomical level, literacy, urban/rural, booked or unbooked etc. Special attention was given on which phase mortality happens, direct and indirect causes. The mean age of the woman was $25.4 \pm 5.4$ years. So, maximum deaths in reproductive age groups. Out of 30 maternal deaths 21-30yrs age group having $77 \%$ of maternal death while $67 \%$ belongs to lower socioeconomical class.23 (77\%) women noted from rural area while only 7 (23\%) women coming from urban area. $18(60 \%)$ were illiterate while only $12(40 \%)$ women had education of below higher secondary level.

Out of 30 majority $15(50 \%)$ deaths were noted in $<24 \mathrm{hrs}$ of delivery while $3(10 \%)$ in $1^{\text {st }}$ stage of labor, 3 $(10 \%)$ in $>24 \mathrm{hrs}$ of delivery and $9(30 \%)$ were noted undelivered.
Hemorrhage was the most common $(50 \%)$ immediate direct cause of death. Others causes were Eclampsia $(13 \%)$, septicemia (11\%), ARDS (13\%), others (13\%). Anaemia was the most common contributory cause of the death among the deceased women $(33 \%)$, jaundice $(13 \%)$ and OTHERS (17\%).

\section{Discussion}

Most of the maternal deaths were seen in women in this study between 21-30 years age group (77\%). The distribution of maternal deaths in different age groups is similar to the pattern of maternal deaths reported in our country [6]. Previous studies in India[7,8,9] and abroad[10] have reported that maternal deaths among referral cases range from $31.2 \%$ to $76.4 \%$ where in this study deaths rate in referred cases were $63 \%$.

There were 30 Maternal Deaths during Study Period of 2 years in the Institute. Maternal Mortality Rate of the Study Centre was 219 per lakhs live births. While in country the MMR in 2010-2012 was 178 per one lakh live births it further dropped to 167 per one lakh live births in 2011-2013. High MMR is due to tertiary centre were most referred and critical cases have been received.

As per WHO 2007 estimates $25 \%$ of all maternal deaths are due to haemorrhage while in our study we have noted it was around 50\% cases. Also as per WHO 2007 eclampsia accounts around $13 \%$ of maternal deaths same has been noted in our study [1].

Sepsis was noted in $10 \%$ cases found around $15 \%$ in WHO 2007 [1].

A vast majority of the maternal deaths (77\%) were noticed amongst women residing in rural areas. The burden of maternal mortality is much higher in rural areas than in urban areas because of factors like poor socio-economic status, inaccessibility to health system and delay in referral.

About more than half of the deceased women were illiterate $(60 \%)$. Poor, illiterate rural women not only have resource constraint but also not self-empowered to take their own decisions or to understand the seriousness of the situation. All these factors often prove critical to their pregnancy outcome. These are the major social risk factors of maternal mortality [7, 12]. 


\section{Conclusion}

Maternal mortality is a matter of global concern, more so in the resource poor settings of underdeveloped and developing countries where most of the deaths occur $[11,12]$.

Maternal Mortality Ratio of the Study Centre was 219 per lakhs live births. Hemorrhage was the most common cause. Early registration, regular antenatal care, early referral are key things in reduction of maternal deaths.

FMBDR has the ability to review deaths both as aggregated data and individually. From the aggregated data come broader themes and trends that can be identified and monitored and with appropriate policy changes and interventions might lead to improvements in outcomes [13]. From the single examination of cases by experts comes information that might otherwise have been over looked [14].

FBMDR should be done at every institute level to find out the deficit and thus helping in reduction of maternal deaths.

\section{Funding: Nil,Conflict of interest: None. Permission of IRB: Yes}

\section{Refrences}

1. WHO, UNICEF, UNFPA, The World Bank. Trends in maternal mortality: 1990 to 2008. Geneva, World Health Organization, 2010.

2. Lewis G. Beyond the numbers: reviewing maternal deaths and complications to make pregnancy safer. $\mathrm{Br}$ Med Bull. 2003;67:27-37.

3. India. Ministry of Health and Family Welfare. Annual Report 1999-2000. New Delhi, Government of India, 2001.

4. Alexandre Dumont, Alioune Gaye, Luc de Bernis, Nils Chaillet, Anne Landry, JoannneDelage, Marie Helene Bouvier-Colle. Facility-based maternal death reviews: effects on maternal mortality in a district hospital in Senegal. Bull World Health Organ 2006; 84: 218-24.
5. Brämer GR. International statistical classification of diseases and related health problems. Tenth revision. World Health Stat Q. 1988;41(1):32-6.

6. Sample Registration System (2011). Special Bulletin on Maternal Mortality in India 2007-09. New Delhi:Registrar General of India.

7. Tayade S.Bagde M.Shivkumar P.Tayade A.Bagde N. Maternal Death Review To Know The Determinants Of Maternal Mortality In A District Hospital Of Central India International Journal of Biomedical Research [serial on the Internet]. 2012 April 1; 3(3): Available from:

http://www.ssjournals.com/index.php/ijbr/article/view/7 25

8. Rajaram P, Agrawal A, Swain S. Determinants of maternal mortality: a hospital based study from south India. Indian J Matern Child Health. 1995 JanMar;6(1):7-10.

9. Nomita Bedi, Indra Kambo, B.S. Dhillon, Badri N. Saxena, Padam Singh. Maternal deaths in India Preventable Tragedies (An ICMR Task Force Study). J Obstet Gynecol Ind Vol.51, No. 2: March/April 2001 Pg. 86-92.

10. Kongnyuy EJ, Mlava G, van den Broek N. Facilitybased maternal death review in three districts in the central region of Malawi: an analysis of causes and characteristics of maternal deaths. Womens Health Issues. 2009 Jan-Feb;19(1):14-20. doi: 10.1016/j.whi.2008.09.008.

11. Hill K, Thomas K, AbouZahr C, Walker N, Say L, Inoue M, Suzuki E; Maternal Mortality Working Group. Estimates of maternal mortality worldwide between 1990 and 2005: an assessment of available data. Lancet. 2007 Oct 13;370(9595):1311-9.

12. Prata N, Graff M, Graves A, Potts M. Avoidable maternal deaths: three ways to help now. Glob Public Health. 2009;4(6):575-87. doi: 10.1080/17441690802184894.

13. NHS Institute for Innovation and Improvement. Reducing avoidable mortality. 2007. Available at: http://www.matrixknowledge.com/wpcontent/uploads/reducing-mortality.pdf.Accessed Sep. 30, 2012.Farquhar C, Sadler L, Masson V, et al. 
Beyond the numbers: classifying contributory factors and potentially avoidable maternal deaths in New Zealand, 2006 -2009. Am J Obstet Gynecol 2011;205:331.e1-8.
14. Sandhu AK, Mustafa FE. Maternal mortality in Bahrain 1987-2004: an audit of causes of avoidable death. East Mediterr Health J. 2008 MayJun;14(3):720-30.

\section{How to cite this article?}

Goswami KD, Dudhrejia KM, Parmar PH, Kataria A. An analytical study of maternal death at tertiary care hospital. Int J Med Res Rev 2015;3(9):1008-1011. doi: 10.17511/ijmrr.2015.i9.186. 